\title{
Diagnosis of Aspergillus niger Peritonitis in a Peritoneal Dialysis Patient by Peritoneal Galactomannan and $\beta$-D-Glucan Detection
}

Editor:

Fungus is an uncommon cause of peritonitis in continuous ambulatory peritoneal dialysis (CAPD). Fungal CAPD-related peritonitis has been associated with high mortality $(22 \%-33 \%)$ and a high rate of CAPD discontinuation $(50 \%-85 \%)$ (1). Here, we report a case of Aspergillus niger peritonitis that was diagnosed in a female patient on CAPD through the detection of $\beta$-D-glucan (BDG) and galactomannan (GM) positivity in peritoneal fluid and plasma. The patient was successfully treated with intravenous amphotericin $B$ and removal of the peritoneal catheter. To our knowledge, this is the first report of peritoneal fluid GM and BDG detection being used for diagnosis in this setting.

A 42-year-old woman with end-stage renal disease caused by nephrolithiasis was admitted with nausea, vomiting, and abdominal pain. She had been maintained on CAPD for 13 years without any complications, including peritonitis. She described a history of diarrhea 10 days before her current presentation.

on admission, her physical examination showed diffuse abdominal tenderness, defense, and rebound tenderness. Laboratory examination revealed a serum white cell count of 9500, an erythrocyte sedimentation rate of $120 \mathrm{~mm} / \mathrm{h}$, and C-reactive protein of $289 \mathrm{mg} / \mathrm{dL}$. Peritoneal effluent was cloudy, with 380 white cells per microliter, $14 \%$ being polymorphs, $68 \%$ monocytes, and $9.6 \%$ lymphocytes. Gram stain of the effluent yielded no neutrophils and no micro-organisms. The subcutaneous tunnel and the catheter exit were unremarkable.

Empiric antibiotic treatment with intraperitoneal (IP) cefazolin $2 \mathrm{~g}$ daily and amikacin $500 \mathrm{mg}$ IP every 5 days was initiated, resulting in mild clinical improvement. Despite negative cultures and an absence of fever, the patient's clinical status worsened and her abdominal pain increased over the following days. Her treatment was changed to vancomycin $1 \mathrm{~g}$ every 5 days IP, while maintaining the amikacin. On the 5th day, the effluent white cell count had increased $(3410 / \mu \mathrm{L})$, with an effluent GM index of 14.6 (Platelia Aspergillus ELISA: Bio-Rad Laboratories, Marnes-la-Coquette, France) and a BDG exceeding $523 \mathrm{pg} / \mathrm{mL}$ (Fungitell kit: Associates of Cape Cod, East Falmouth, MA, USA). For those reasons, the Tenckhoff catheter was removed, and the patient was switched to hemodialysis. Intravenous treatment with amphotericin B was started. 0n day 7, fungal 
species were isolated from the peritoneal catheter. Plasma BDG was $523 \mathrm{pg} / \mathrm{mL}$, and the GM index was 1.05 . Computed tomography imaging of thorax and abdomen revealed no pathology. 0 n day $10, A$. niger was isolated from the Tenckhoff catheter culture, with sensitivity to amphotericin B.

Filamentous fungi have only rarely been identified as causative agents in peritonitis complicating CAPD. The types of filamentous fungi reported to have caused CAPDrelated peritonitis include Aspergillus, Paecilomyces, Penicillium, Acrimonies, Fusarium, and Zygomycetes (2). In most peritonitis cases caused by Aspergillus, the causative agent has been found to be $A$. fumigatus, $A$. terreus, $A$. flavus, or $A$. niger. Peritoneal dialysis-related peritonitis caused by $A$. niger has been described 5 times previously in the literature $(3,4,5)$.

Despite the availability of newer antifungal drugs, outcomes in patients with invasive fungal infections continue to be poor because of delayed diagnosis and initiation of appropriate antifungal therapy. Diagnosis of invasive aspergillosis is even more difficult. Standard histopathologic diagnostic techniques and culture-based diagnostics typically take too long to allow for optimal treatment. Newer surrogate markers of invasive fungal infection are needed to hasten diagnosis and permit therapeutic monitoring. Clinicians have recently been using several adjunctive methods, such as GM antigen detection or BDG assay.

Galactomannan is a component of the Aspergillus species cell wall that is released into the surrounding environment during fungal growth or tissue invasion (6). In 2003, the US Food and Drug Administration approved the use of a double-sandwich GM enzyme immunoassay (Platelia Aspergillus EIA: Bio-Rad Laboratories) for the diagnosis of invasive aspergillosis in adult patients (7). The double-sandwich ELISA for detection of GM is reported to have high sensitivity and high specify for invasive aspergillosis when a cut-off value of $0.8 \mathrm{ng} / \mathrm{mL}$ is used (8).

The polysaccharide BDG is located in the cell membrane of most fungal pathogens, notable exceptions being Mucor and Cryptococcus species $(6,9)$. Small quantities of $\beta$-glucan are released into blood during an invasive fungal infection, and the Fungitell Assay can detect $\beta$-glucan in serum, providing results within 2 hours (10). A number of commercially available methods use various methodologies, cut-off values, and sensitivities to detect BG. The chromogenic BDG test (Fungitell Assay) was approved by the Food and Drug Administration as an adjunct (6). The assay uses a blood coagulation factor (factor $G$ ) isolated from blood cells of the North American horseshoe crab to selectively detect $\beta$-glucan in a colorimetric assay $(6,10)$. An important study by a group of Japanese researchers, which appeared in The Lancet in 1995, demonstrated high sensitivity (90\%), specificity $(100 \%)$, and negative predictive value $(97 \%)$ for invasive mycosis with the use of a BDG assay and a plasma cut-off value of $20 \mathrm{pg} / \mathrm{mL}$ in febrile patients (11). The present report suggests that the BDG assay and GM index previously suggested as useful in the management of invasive fungal infections in neutropenic hematologic patients may be suitable for application in the early diagnosis of fungal peritonitis.

\section{DISCLOSURES}

The authors have no financial conflicts of interest to declare.

$$
\begin{aligned}
& 0 . \text { Ates }^{1 *} \\
& \text { G. Metan }{ }^{2} \\
& \text { T. Dundar }{ }^{3} \\
& \text { M. Kiziltepe }{ }^{3} \\
& \text { I. Kocyigit }{ }^{1} \\
& \text { A. Unal }{ }^{1} \\
& \text { M. Sipahioglu }{ }^{1} \\
& \text { 0. } 0 \text { ymak }^{1} \\
& \text { B. Tokgoz }{ }^{1}
\end{aligned}
$$

\section{REFERENCES}

1. Bren A. Fungal peritonitis in patients on continuous ambulatory peritoneal dialysis. EurJ Clin Microbiol Infect Dis 1998; 17:839-43.

2. Wang AY, Yu AW, Li PK, Lam PK, Leung CB, Lai KN, etal. Factors predicting outcome of fungal peritonitis in peritoneal dialysis: analysis of a 9-year experience of fungal peritonitis in a single center. Am J Kidney Dis 2000; 36:1183-92.

3. Bibashi E, Papagianni A, Kelesidis A, Antoniadou R, Papadimitriou M. Peritonitis due to Aspergillus niger in a patient on continuous ambulatory peritoneal dialysis shortly after kidney graft rejection. Nephrol Dial Transplant 1993; 8:185-7.

4. Sridhar R, Thornley-Brown D, Kant KS. Peritonitis due to Aspergillus niger: diagnostic importance of peritoneal eosinophilia. Perit Dial Int 1990; 10:100-1.

5. Rodriguez-Tudela JL, Barros C, Aguado JM, Gomez-Garcés 
JL, Velo M, de Arriba G. Aspergillus niger peritonitis. Nephrol Dial Transplant 1988; 3:232.

6. Hsu JL, Ruoss SJ, Bower ND, Lin M, Holodniy M, Stevens DA. Diagnosing invasive fungal disease in critically ill patients. Crit Rev Microbiol 2011; 37:277-312.

7. Petraitiene R, Petraitis V, Groll AH, Sein T, Piscitelli S, Candelario $M$, et al. Antifungal activity and pharmacokinetics of posaconazole ( $\mathrm{SCH}$ 56592) in treatment and prevention of experimental invasive pulmonary aspergillosis: correlation with galactomannan antigenemia. Antimicrob Agents Chemother 2001; 45:857-69.

8. Maertens J, Theunissen K, Verbeken E, Lagrou K, Verhaegen J, Boogaerts $\mathrm{M}$, et al. Prospective clinical evaluation of lower cut-offs for galactomannan detection in adult neutropenic cancer patients and haematological stem cell transplant recipients. Br J Haematol 2004; 126:852-60.

9. Preuner S, Lion T. Towards molecular diagnostics of invasive fungal infections. Expert Rev Mol Diagn 2009; 9:397-401.

10. Associates of Cape Cod. Fungitell Assay [Web page]. East Falmouth, MA: Associates of Cape Cod; n.d. [Available at: http://www.acciusa.com/clinical/fungitell/index.html; accessed 28 August 2011]

11. Obayashi T, Yoshida M, Mori T, Goto H, Yasuoka A, Iwasaki $\mathrm{H}$, et al. Plasma $(1 \rightarrow 3)-\beta$-D-glucan measurement in diagnosis of invasive deep mycosis and fungal febrile episodes. Lancet 1995; 345:17-20.

doi:10.3747/pdi.2012.00042 